\title{
Loneliness and housing tenure: Older private renters and social housing tenants in
}

\section{Australia}

\section{Introduction}

Globally, loneliness is viewed as a critical social issue and one of the major health concerns of the contemporary period (Caciappo et al. 2009; Cacioppo and Cacioppo 2018; HoltLuns tad et al. 2015; López Doblas and Díaz Conde 2018). There is a recognition that if left untreated, it can have serious implications for physical and mental health (Gerst-Emers on and Jayawardhana 2015; Hawkley et al. 2010; Holt-Luns tad et al. 2015; Victor and Yang 2012). In this article, we focus on older Australians reliant on the government Age Pension for their income residing in social housing or the private rental sector (PRS). We show that housing tenure is a crucial determinant of loneliness for this cohort; older private tenants were far more likely to be lonely than their social housing counterparts.

Although there is some overlap, there is agreement we need to distinguish loneliness from social is olation (Malcolm et al. 2019). A person who is devoid of social contacts is not necessarily lonely and having a number of social contacts does not preclude an individual experiencing loneliness. The quality of a pers on's social contacts is crucial (Franklin and Trantor 2011; Holt-Lunstad et al. 2015; Victor et al. 2009). As Routasalo and Pitkala (2003, 303) conclude, "A person may suffer from loneliness even though surrounded by many people, whilst an is olated pers on may feel completely content with their situation". Loneliness is premised on a lack of satis fying human relationships that causes distress for the individual concerned (Savikko et al. 2005). A widely accepted definition of loneliness is that 
it involves an unwanted discrepancy between the relationships one has and the relationships one would like to have:

Loneliness is a perceived deficit between actual and desired quality or quantity of relationships [whereas] [s] ocial is olation is the objectively quantified shortfall in an individual's social relations hips often measured in terms of social network size, diversity or frequency of contacts (Malcolm et al. 2019: 2).

Although dis tinct concepts, there is a strong relationship between social is olation and loneliness. People who are socially is olated are more like to experience loneliness than are people who have a number of social contacts (AIHW 2019; Yildrim and Kocabiyik 2010).

While difficult and contentious to measure (see Beer et al. 2016; Stanley et al. 2010), national and comparative surveys suggest that a substantial proportion of the global population experiences loneliness at some stage in their life and that the prevalence is increasing (Franklin and Tranter 2011; Holt-Lunstad et al. 2015). One estimate is that in advanced economies around a third of the population are affected to some degree by loneliness, and one in 12 are severely affected (Cacioppo and Cacioppo 2018). A 2010 survey in the United States concluded that around a third of Americans over 45 felt lonely (Anders on 2010). In the United Kingdom, a survey by the British Red Cross found that $18 \%$ of respondents felt lonely always or often (B ritish Red Cross 2017). The perceived cris is around loneliness led to the British Parliament appointing its first minister for loneliness in January 2018. In Australia, a nation-wide study by the Australian Psychological Society found that one in four Australian adults experience loneliness. In response to the question: 'How often do you feel alone?' $8.5 \%$ of res pondents answered 'always' and $41.4 \%$ said 'sometimes'. Close to $30 \%$ reported they rarely or never feel 'part of a group of friends' (Australian Psychological Society 2018). 
Comparative studies suggest that the broader national economic, social and cultural context perhaps influences the extent of loneliness. A study comparing the extent of loneliness in the UK, the United States of America and Japan, found that $22 \%$ of adults in the United States often or always felt lonely, as do $23 \%$ of adults in the UK. The extent of loneliness in Japan was far lower with $9 \%$ of respondents stating that they often or always felt lonely (Di Julio et al. 2018). Noteworthy, is that the majority of people experiencing loneliness in this study were under 50 .

The European Social Survey (ESS) investigated loneliness and age across 25 European nations. It found that Eastem European nations have the highest proportion of lonely people and Northem Europe the lowest (Yang and Victor 2011). The survey showed that in Russia and other Eastern European nations, loneliness is highest in the older age cohorts. The same survey found that in Northern European countries loneliness was far less prevalent and did not increase with age.

A survey of loneliness among older people (12,248 responses) in 14 countries in north, south, east and central Europe found that respondents in Denmark, Switzerland, The Netherlands, Germany and Sweden were located on the low side of feelings of loneliness and the Czech Republic, Greece, Spain, France, Poland and Italy were on the high side. Thus in Denmark, $6.3 \%$ of respondents recorded the lowest "feelings of loneliness", compared to $20 \%$ of Polish and 25.4\% of Italian respondents (Fokkema, et al. Dyks tra 2012). A multivariate analys is es tablished that the higher prevalence of loneliness in Greece and the Czech Republic was due to their populations being older, having a higher proportion of older women and of never and formerly married older people. Diffe rences in socio-economic status was also a major factor accounting "for the higher level of loneliness in the central European countries Poland 
and the Czech Republic and in the southem European countries Greece, Spain, and Italy ... “ (Fokkema et al. 2012: 215). Health status was also central, explaining the high levels of loneliness in Spain. Having children and being in contact with them was significant: "The largest differences in the prevalence of loneliness are found between older adults with and without children" (Fokkema et al. 2012: 219).

The prevalence of loneliness in late modernity has been linked to the collapse of traditional structures and the expectation that the individual has to make their own way in the world. The array of possibilities, whilst liberating, also increases the risk of loneliness. This openness and attendant risk is captured by Giddens (1991: 5).

Because of the 'openness' of s ocial life today, the pluralisation of contexts of action and diversity of 'authorities', lifestyle choice is increasingly important in the cons titution of self-identity and daily activity. Reflexively organised life-planning, which normally presumes consideration of risks as filtered through contact with expert knowledge, becomes a central feature of structuring self-identity.

A similar argument is made by Beck and Beck-Gernsheim (1996: 27). They contend that a key feature of the contemporary period is individualisation. Individuals need to construct their own trajectory and this process is fraught with risk. If they fail, loneliness could result.

... if they are not to fail individuals must be able to plan for the long term and adapt to change; they must organise and improvise, set goals, recognise obstacles, accept defeats and attempt new starts. They need initiative, tenacity, flexibility.

An aspect that has received minimal attention is the impact of housing tenure on loneliness. This study contributes to this sparse literature on housing and loneliness by examining the impacts of housing tenure on loneliness among older people (65 and over) in Aus tralia. 
Drawing on in-depth interviews, it compares the perceptions and experiences of loneliness of older private renters to that of older social housing tenants. While recognising that the causes of loneliness are varied and complex, we argue that in Australia, for older people on the government Age Pension ${ }^{1}$, their housing tenure often plays a critical role in shaping their experience of loneliness. The study compares older private renters to older social housing tenants. It illus trates how the insecure and expensive private rental sector (PRS) (s ee Aus tralian Government 2019) in contrast to the secure and affordable social housing sector, means that older private renters are more likely to experience loneliness than their social hous ing counterparts.

The article proceeds as follows; next loneliness is defined and distinguished from social is olation. We then examine the contributors to loneliness focusing on older people. This is followed by a discussion of housing tenure and loneliness. Housing tenure in the Aus tralian context is then briefly reviewed and the methodology outlined. Following this, the research findings on the experience of loneliness of older Australians in the PRS and their counterparts in social housing are mapped out.

\section{Contributors to loneliness focusing on older people}

A common notion is that loneliness among older people will be higher than the general population due to a range of potentially challenging transitions - increased health problems, retirement from work, children leaving home and death of spouse, friends and relatives (Heylen 2010; Routasalo and Pitkala 2003; Stanley et al. 2010). Certainly, widowhood can be a major determinant of loneliness for older people (Beer et al. 2016; De Jong Gierveld and Havens 2004; López Doblas and Díaz Conde 2018). A key shift over the last three decades in almost all advanced economies has been the increase in the proportion of single pers on households. Research has consis tently demonstrated that while not everyone that lives alone 
experiences loneliness, it certainly increases the possibility (Holt-Lunstad et al. 2015; Fors man et al. 2013). An Aus tralian study concluded that loneliness is highly concentrated in single pers on households where $40 \%$ of res pondents who lived alone (all age groups ), agreed that they experienced loneliness (Franklin and Tranter 2011). In Australia, lone pers on households increased from $20 \%$ of all households in 1991 to $24.4 \%$ in 2016 (ABS 2017a). In $2016,22.9 \%$ of households occupied by pers ons aged 65 and over were single pers on households (ABS 2017b).

Health status has als o been found to be a significant contributor to loneliness (Malcolm, Frost and Cowie 2019; Savikko et al. 2005). Older people with low physical functioning are more likely to experience loneliness as mobility difficulties may be a barrier to social engagement (Aartsen and Jylhä 2011; Cohen-Mans field and Parpura-Gill 2007). Not surprisingly, social is olation and loneliness have been found to be greater for older people with vis ual or hearing impairment as their capacity to sus tain social connections is diminished (Grow et al. 2015; Kramer et al. 2002). The lessening of s ocial relationships due to poor physical health, can lead to depression which further exacerbates withdrawal and loneliness (Malcolm et al. 2019). Depression has been strongly associated with loneliness and over time they mutually reinforce each other (Yang 2019). In their study of age and loneliness, Victor and Yang (2012: 96) found that, 'Those who report that they are depressed all or most of the time have the highest reported rates of loneliness at approximately $38 \%$ '.

Contact with adult children and grandchildren can play an important role in preventing loneliness. When there is limited communication and contact across generations, there is a greater chance of the older people affected experiencing loneliness (De J ong Gierveld and Havens 2004). A study of older people in Finland described how grandchildren gave meaning to life and concluded that inter-generational relationships were perceived as an important part 
of their wellbeing (Fors man et al. 2013).

Besides societal factors, the personality of individuals is an important as pect to consider. In an Australian study of 764 adult twins, significant positive correlations were found between loneliness and insecurity / stress (neuroticis m) and significant negative correlations were found with agreeableness, conscientious ness and extraversion (Schermer and Martin 2019).

\section{Housing tenure and loneliness}

The role of housing tenure, as mentioned, has received minimal attention in the discussion of contributors to loneliness. The relationship between housing tenure and loneliness is complex and disentangling causality is difficult. Nevertheless, previous research has indicated that the re is a link. An Australian survey of 1502 Australian adults found that renters (private rental and social housing tenants ) are significantly more likely to experience loneliness than homeowners. Whereas only $4 \%$ of homeowners said that they experienced loneliness on a daily basis, $11 \%$ of social housing tenants and $13 \%$ of private renters did (Franklin and Tranter 2011). The same survey found that $62 \%$ of outright homeowners, $27 \%$ of s ocial housing tenants and $39 \%$ of private renters said that they rarely or never experience loneliness.

Franklin and Tranter's explanation for the results highlights the difficulty of is olating housing tenure as a causal factor. Although their explanation for the differences is sparse, they do indicate that household composition is a key factor. Thus almost half of respondents who lived alone "agreed that they experience loneliness as a serious problem". In Australia, a far greater proportion of older renters live alone. The 2016 Australian Cens us indicated that $24.2 \%$ of homeowners lived alone compared to $42.1 \%$ of renters (unfortunately the social housing and private renters data were pooled) (ABS 2017). The same study found that selfrated health status was a strong predictor of loneliness: 'Those in poor health ... [were] 
almost five times as likely as those in good or excellent health to experience loneliness frequently ...' (Franklin and Tranter 2011: 7). The self-reported health status of the social housing tenants was much lower than that of homeowners and the private renters. Finally, social class was a factor. Respondents who identified as lower class tended to be more lonely than those who identified as middle class. The older homeowners were far more likely to be middle class than the social housing tenants or private renters.

Another key factor linked to housing tenure is stability of residence. Research has indicated that longevity of residence can contribute to close social ties and mutual ass is tance (Kasarda and Janowitz 1974; Keene et al. 2013; McCabe, 2012; Turney and Harknett 2010). In their study of neighbourhoods in Chicago, Keene et al. (2013: 174) concluded that the "Mean levels of social support, nearby social ties, social cohesion and reciprocal exchange, are generally higher for longer-term residents".

Affordable, safe and adequate housing is als o an important determinant of health status and wellbeing (Meltzer and Schwartz, 2012; Maqbool et al. 2015). Households who are not in affordable and adequate housing are far more likely to suffer from stress and poor health which in turn can have a significant impact on people's capacity to form quality social bonds (de Jong and Tesch-Romer 2012: Burholt and Scharf 2014). Home ownership has been shown to contribute towards ontological security (His cock et al. 2001).

\section{Housing tenure and people dependent on the government Age Pension in Australia}

His torically, Australia has been a home-owning society. Home ownership expanded rapidly post 1945 reaching $72 \%$ in 1962, up from 47\% in the late 1940s (Paris 1993). Since this highpoint, there has been a slow but steady decline. In the last decade es pecially, accessing home owners hip has become exceptionally difficult for low-income households. In 2017-18, 
$66 \%$ of Australians owned their home with or without a mortgage (ABS 2019a). Social hous ing has never exceeded $6 \%$ of the housing stock and in 2017-18 cons tituted only $3 \%$ (ABS 2019a). Historically, social housing, although a small proportion of the housing stock, has played a critical role in hous ing low-income households (Paris 1993). The PRS has shown a steady inc rease and in $2017-18,27 \%$ of all households were private renters, up from $20 \%$ in 1997-98 (AB S 2019a). In 2017-2018, 83.6\% of households where the age of the reference pers on was aged 65 plus were homeowners, $9.1 \%$ were private renters (up from $6.5 \%$ in 2003-04) and 3.3\% were social housing tenants (ABS 2019b).

The significance of housing tenure for people dependent on the government Age Pension is illustrated in the most recent Australian Bureau of Statistics (ABS) data on the cost of housing. In 2017-18, the mean national weekly cost of housing for homeowners without a mortgage was $\$ 53$, for homeowners with a mortgage it was $\$ 484$, for social housing tenants it was $\$ 158$ and for tenants of a private landlord it was $\$ 399^{2}$ (ABS 2019b). The maximum Age Pension (including supplements) for people living by themselves in July 2018 was $\$ 425$ a week and for a couple it was $\$ 642$. Private renters dependent on government benefits are als o entitled to Rent Ass is tance (RA) - a payment from the federal government to help them with their rent. The maximum RA a sole pers on household could receive in July 2018 was $\$ 67.40$ a week and a couple was entitled to $\$ 63.50$ a week. Table 1 shows the proportion of income that was required by households in July 2018 in the different tenures presuming they were paying the mean national weekly housing costs and receiving the full government Age Pension and in the case of private renters, receiving the maximum CRA.

\section{Table 1 here}


Table 1 illus trates that older homeowners and social housing tenants dependent solely or primarily on the Age Pension for their income are likely to have substantially greater financial resources at their disposal than their private renter counterparts due to the cost of their accommodation being so much lower. The rent of social housing tenants is set at a maximum of $25 \%$ of income. In contrast, an older private renter paying the mean weekly rent and living by themselves would be using $85 \%$ of their income to pay for accommodation. After paying their rent, the dis posable weekly income of a social housing tenant living by themselves and dependent on the Age Pension for their income, would be $\$ 319$ dollars. The weekly dis posable income of their counterpart in the PRS would be \$93. The minimal dis posable income of this group encourages loneliness. They simply do not have the financial capacity to maintain social ties and socially engage.

Besides being affordable, a crucial advantage of social housing is that security of tenure is virtually guaranteed. Potentially they can be resident in the same property for many years. In contrast, in the PRS once the written agreement/lease with the landlord ends (leases are rarely more than 12 months), in New South Wales (NSW), the state where this research took place, the tenant can be evicted as long as s/he is given 90 days written notice. The landlord is not required to give reasons. Also, once the lease ends the landlord can increase the rent to whatever the market can bear. This scenario means that unless they have a benevolent landlord, older private tenants live in perpetual fear of being asked to vacate or of having their rent increased to an untenable level (Australian Government 2019).

\section{Methodology}

This analys is draws on interview data drawn from 32 semi-structured in-depth interviews with older (65 plus) private renters and 62 social housing tenants. In order to make the two groups as similar as possible, all couple households were excluded from the sample. Thus all 
of the interviewees were living by themselves and dependent on the government Age Pension solely or primarily for their income. They were all aged 65 or over. The average age of the private renters interviewed was 71 and for the social housing tenants it was 73 . Twelve of the 32 private renters were male and 20 were female. Only 14 of the social housing tenants interviewed were male. Interestingly, gender did not emerge as a factor in the responses of interviewees. Almost all of the interviewees were living in Sydney. A few of the private renters were located in regional towns in NSW. The interviews were conducted between 2005 and 2017.3

All of the interviews with the private renters and 43 of the interviews with social housing tenants were conducted as part of a larger project (project 1) that examined the various impacts of housing tenure on older Australians dependent on the government Age Pension for their income. A key focus was the impact of housing tenure on social ties, leisure activities and the experience of loneliness.

The remaining 19 interviews were all with social housing tenants in inner-Sydney. ${ }^{4}$ These interviews, conducted in 2016 and 2017, were part of a project (project 2) that examined the impacts of the dis placement of a long-standing social housing community in Millers Point in inner Sydney (see author, 2018). Some of the tenants interviewed had already moved. By July 2018, all of the close to 600 social housing tenants had been moved. Again, a key theme in these interviews was the social ties, sense of community and mutual ass is tance that existed in the area prior to the dis placement announcement in early 2014. For the 11 interviewees who had moved, an additional theme was the impact of the dis placement on their social ties and experience of loneliness. 
All of the interviews were audio-recorded and professionally transcribed. Each transcript was then saved on NVivo s oftware. Adopting an inductive approach, the interviews were studied line by line and all material relating to the experience of loneliness, what contributed to it or lessened it, the quality of social ties and a sense of social integration, were identified.

\section{Recruitment}

There is potential for bias in any study involving the recruitment of interviewees. However, the recruitment strategy meant that any older social housing tenant or private renter who saw the recruitment material was able to accept the invitation to participate. The only criterion was that they needed to be reliant on the Age Pension for their income. Recruitment of the social housing tenants and private renters for project 1, involved visiting social housing complexes, liaising with tenants' committees, asking organis ations that support and have contact with older people to assist with recruitment, advertising the study in a seniors publication, flyers and snowball sampling. The social housing tenants, because they are generally concentrated in a housing complex, were not difficult to recruit. Eight interviewees were based in Western Sydney, the remainder were all in the inner-city in Sydney.

For project 2, the committee formed to fight the Millers Point dis placement played a major role in advertising the study and recruiting tenants. The lawyer representing the tenants also ass is ted and again there was little problem finding participants.

In contrast, the recruitment of the older private renters was a major challenge. This was mainly due to them being dispersed, is olated and less engaged with organis ations. For these interviewees, word of mouth was crucial as was an advertisement for the study placed in a widely circulated free seniors publication.

\section{Older private renters and loneliness}


Despite the epis temological difficulties, the interviews strongly indicated that the interviewees who were dependent on the PRS for their accommodation were much more likely to be socially is olated and experience loneliness than their counterparts in social housing. The two fundamental features of the PRS that created fertile ground for older tenants in the PRS experiencing loneliness were the high cost of their accommodation relative to their income and their tenure insecurity. These two features had five inter-related consequences all of which contributed to social is olation and loneliness. They were a lack of financial resources, insecurity, anxiety and depression, inappropriate accommodation and being located in an unsuitable neighbourhood. The few private tenants who had managed to find empathetic landlords and felt secure and were paying a low rent, were generally socially engaged and less likely to experience loneliness.

Financial stress, insecurity, anxiety, depression and loneliness

The financial stress and insecurity of most older private renters had two key impacts. It meant that they had little or no money for social activities and this made it exceptionally difficult for them to maintain social ties and break their is olation. Secondly, their lack of financial res ources combined very often with the constant concern that they could be forced to move, created intense anxiety and, in some cases, depression.

Betty (all the names used are pseudonyms) was a widower. She als o could not afford to engage in social activities and was desperately lonely. Her rent exceeded her income and she depended on her daughter to make up the shortfall. Her daughter purchased all her necessities: 
Without her [her daughter], I couldn't live. Yeah, [I feel is olated] and everybody says, “Well I'm going to such and such, its free, would you like to come?”... I've got nothing decent to wear.

Her financial situation was a central contributor to her loneliness and depression. She hardly ventured out:

I do think that when it gets to the stage where the Age Pension doesn't even cover your net [expenses], I do think you should be entitled to take something ... I us ually ring Lifeline when I feel that I want to commit suicide to tell you the truth. ... I don't sleep at all at night now. I'm so worried about it all ... I don't suppose you're meant to have dignity now ... I used to volunteer, but I've just got so down, now I just haven't got the energy.

Another older private renter, Barbara was in a similar situation. Her rent accounted for a large part of her income and her limited finances meant she could not participate socially. Her loneliness was acute:

What do you do with $\$ 40$ ? Can’t pay the electricity, can’t pay the gas, can’t pay the phone. You cannot do anything ... Well, you don’t go anywhere!

Shirley was desperate to access social housing and was becoming increasingly depressed, is olated and lonely. Her comment is a stark illustration of the link between housing costs, the resultant lack of financial resources, depression and loneliness:

Well it [being a private renter] is having a lot of emotional impact. My doctor gets quite concerned about my situation. She's written several letters herself filling forms and everything to the Housing Commission to try and get me [in] quicker ... And it [being a private renter] and having [restricted finances] affects you really badly 
mentally ... So you know it stops you from socialising ... I don't go to the movies. I don't go to the clubs. I don't go anywhere.

For some older private renters their social isolation due to financial cons traints did not necessarily equate to feeling lonely. Bill's hobby kept him occupied:

Yes, well I don't go out. I haven't been able to go out for ages ... Life is quite restrained you might say. I mean I'm s ort of, in a different position to s ome of the other people because I have a great interest in the internet and I paint ... So, I mean that's what I can do. I can restore pictures. I've done it for ages and that was a hobby for the last 10 years ... I wouldn't mind company but the thing is I can entertain myself to some degree, but other people if you didn't have that sort of drive to do something like that you'd be sitting around all day waiting for the next day ...

The accommodation, the neighbourhood and loneliness

For some private renters, their accommodation accentuated their is olation. Ruth had been forced to live in boarding houses for a period. She found it a deeply is olating and difficult experience:

You're cohabitating with the most desperate people in our community ... Safety is an issue ... So it is very confronting and you feel very is olated and alone and helpless because there doesn't seem to be anyone you can go to ... I was so entrapped in my own despair that I couldn't, I didn't know how to reach out to services that probably were available and no one was offering anything and everywhere I went the doors were closed so I s ort of gave up. 
Robert lived in a furnished studio, in a rundown apartment block in inner-Sydney. He had no relationship with his neighbours many of whom were transient and had mental health and or substance abuse issues. His is olation was intense, as was his loneliness:

You're is olated and ... you've really got no one to talk to ... It's like being in a gaol ... 'cos you're sitting there looking at four walls and you have no condition that you want to get out.

Their limited finances meant that older private renters had very limited or no capacity to choose where they wanted to live. They would find themselves in neighbourhoods where they would not know anybody. Nancy had been living with her daughter and her family, but had been forced to leave:

I'm very bored and all that sort of thing and lonely and isolated where I am now ... It's [the rented accommodation] very is olated ... I don't know any neighbours and I never see any neighbours. I know they live here, but I don't know where they go to ... When you haven't got [stable] housing, you don't have the neighbours that you know and the shopkeeper that you know. You don't go for morning coffee with your friends. Everything is like living on a razor's edge.

The few older private renters interviewed who had been fortunate to find affordable, secure and adequate accommodation were far less likely to experience loneliness. Rachel's rent was low and her landlord had told her that she could stay in her cottage as long as she desired. I asked her if the low rent and security of tenure meant that she "could participate in society". Her res ponse was clear:

Certainly I do, and I think, as I said, doing the volunteer work makes you feel that you are making a difference you know. I do that a few weekends a month. I get a lot out of that and I do other things as well ... 


\section{Older social housing tenants and loneliness}

Certainly, some of the older social housing tenants interviewed experienced loneliness. This was es pecially so for those who had been dis placed. However, the affordability and security of their accommodation, longevity of residence (this was a crucial factor), similar life his tories of fellow tenants and capacity to walk to friends (fellow tenants living in the same complex), created a context that meant that as a group, they were less likely to experience loneliness than their counterparts in the PRS.

Whereas many of the private renters spent their days alone, only leaving their home to purchase essentials or for religious services, most of the social housing tenants participated in a range of activities, many of which were within walking dis tance. They were not cons trained by a lack of finances or anxiety about the future of their accommodation. Elaine's (72 years old) social engagement was exceptional:
Ah, [I participate in] plenty [of leisure activities ] ... We go to different places and play bowls and we have a walking group, and I belong to a singing group. We go to nursing homes. Twice a week we go to nursing homes. I'm with the choir ... And we've got a concert coming up on Friday, our own concert ... And we go to festivals. Anywhere they want us to sing. I'm very happy.

Some of the public housing tenants were proactive and highly engaged in community activities. Alice was 85 years-old when I interviewed her. She taught English in the community centre of her public housing complex:

There's a lot of good people here, a lot of friendly people ... Now I teach English down here. I'm a voluntary English teacher ... So there's about four or five us now that's permanent and we're there [the community centre] every week. 
Maureen treasured her social housing complex. She had close social ties and felt it was a genuine community:

I think it's wonderful here. As I said, you walk out the door and it lifts you. I think it's a wonderful place. I feel at home and we have no problems here. ... I get on well with everyone ... Everyone, everyone is so nice ... I'm really happy. I'm very pleased.

Tracey loved her public housing apartment block in inner-Sydney:

Well we were so joyous you know and everyone that moved in here, well we knew everyone. We had wonderful neighbours we've never not had wonderful neighbours. And it was just this vibrant hub ... So everyone knew Tracey you know cos we lived there and worked there as well and we just loved it.

The interviewees who had been private renters spoke about how accessing social housing had changed their lives:

I started cooking again. I started gardening again. I started being involved in the community at different levels ... I started socialising with others within the complex where I was living as well ... I had a base. I had a secure private place that was mine. (Ruth)

There were social housing tenants that were lonely. The lack of longevity of residence was clearly a key factor. Wendy had only been in social housing for a few months when interviewed. It was evident that she was terribly lonely. Prior to moving into social housing she had been in a private home looking after a frail older pers on. She now had no obligations . I sugges ted that she is now "as free as a bird". She responded,

I'm not really cos birds are allowed to fly around. I can't. I don't like being here on my own ... It's very lonely because these other tenants they've got their husbands or their 
own lives to live and so they don't mix and so I look at four walls. TV doesn't interest me and I do reading and things like that. But without someone to talk to, it gets a bit monotonous.

Many of the recently dis placed Millers Point tenants were lonely in their new context:

Well no I miss being able to walk out the front door and know people. I feel a lot more lonely ... Since I've been here not one of my friends has been to visit me (Jacinta).

\section{Discussion and conclusion}

Research on loneliness among older people has focused on the significance of health status (e.g. Gerst-Emerson and Jayawardhana 2015), lack of mobility (Aarts en and Jylhä 2011; Cohen-Mans field and Parpura-Gill 2007), living alone and widowhood (López Doblas and Díaz Conde 2018) and on the broader societal context (Victor and Yang 2011). Most of these studies have used surveys with different scales to meas ure loneliness (cf. e.g. Australian Ps ychological Society 2018). To the best of our knowledge, there have been no previous qualitative studies that have explored how older people in different hous ing tenures experience loneliness. Our study partially addresses this research gap and maps the impacts of housing tenure on older people's experience of loneliness. It brings to the fore the need to address the connection between loneliness and housing tenure.

The interviews indicated that housing tenure was a fundamental factor determining the likelihood of experiencing loneliness. Not surprisingly, the crucial as pects were the cost of accommodation and security of tenure. For most of the older private renters, their rent accounted for a substantial fraction of their government Age Pension. After paying for their accommodation, electricity/ gas, telephone and food - the four essential items - most did not have the financial means to partake in social activities and maintain or develop social ties. 
This was es pecially so for those older private renters who lived by themselves and had minimal or no contact with family.

Als o, the possibility of being asked to vacate was a constant concern. Their lack of financial res ources, combined with their constant ins ecurity and perceived lack of control, were key factors generating depression and anxiety about the future. Their mental health exacerbated their incapacity to engage socially and the likelihood of experiencing loneliness.

A final factor was that their limited resources meant that often they were often forced to accept sub-standard accommodation and some found themselves having to live in neighbourhoods where they knew no one. There is no doubt that in many instances their living circumstances accentuated their sense of hopelessness and experience of loneliness.

In many ways the situation of older Australians in PRS reflects the potential impacts of late modemity for the individual. All of these older private tenants had to make their own way in the housing market and have found themselves in the high risk PRS - a housing tenure that can strip away any semblance of community for low-income tenants.

As indicated, a few of the social housing tenants interviewed were lonely. However, in contrast to the private renters, almost all of the social housing interviewees felt that their lives were manageable and that they were part of a community. Due to their accommodation costs being a fixed and manageable percentage of their income, they were able to budget and engage in leis ure activities. Also, they had no fear of losing their accommodation. This security of tenure meant that many of the interviewees had been in the same home for many years, knew their fellow residents and had had ample time to develop deep friendships. Many of their friends lived in the same complex or close by and there was a good deal of mutual support. In line with other studies (see Kasarda and Janowitz 1974; Keene et al. 2013; McCabe 2012), longevity of residence was key. Many of the social housing tenants who had 
recently moved into social housing or had been dis placed from Millers Point were lonely. The ex-Millers Point residents desperately missed the social ties and sense of community they had had.

The sense of security and feeling of belonging and community that the social housing tenants expressed clearly had a positive impact on their mental health. A number were involved in community activities and they were keen and able to engage socially. Research on loneliness emphasises the role of community engagement in reducing the possibility of depression (Fors man et al. 2013).

Although older people, more es pecially the very old (80 plus), are likely to experience lifechanging transitions that could precipitate loneliness (namely widowhood and losing friends through dementia or death), our research supports the finding that age is not necessarily a central determinant, rather it is the circumstances in which older people find themselves. Although national differences are important to consider, what our study shows is that within nations the variations in the circumstances of older people can be profound and have a substantial bearing on whether a particular group of older people experiences or does not experience loneliness. An interesting question for future research is whether more recent and younger social housing tenants have strong social ties or are is olated.

As Australia moves away from being a home-owning society, the role of housing tenure in shaping the extent of loneliness will become more evident. His torically, most older Australians have been able to avoid the PRS in their retirement. There was a realisation that the high housing costs and insecurity linked to this housing tenure, would make everyday life on the Age Pension extremely challenging. Regrettably, the decline of the social housing sector, difficulty accessing home ownership due to the high cost of residential property and 
increasing divorce in later years, means that it is likely that the dependence of older Aus tralians on the PRS will continue to inc rease. This study indicates that an inevitable consequence of this, is that in the future an ever greater proportion of older Australians will experience loneliness.

${ }^{1}$ In Australia, his torically, the government Age Pension has been available for men when they turned 65 and for women when they turned 62. However, the qualifying age has gradually crept up and it is now 66 for men and women and by 2023 it will be 67 . An individual's eligibility is means tes ted - i.e. the amount you are you eligible for is dependent on your income and assets. A pers on's home is not included in the assets test. In February 2020, the full Age Pension, including all supplements, was $\$ 467$ a week for a single person and $\$ 703.50$ for couples. The national minimum wage at this time was $\$ 740.80$ for a 38 hour week.

${ }^{2}$ In Sydney, Australia's most expensive housing market, the median weekly rent for a two bedroom house in June 2019, was around \$600 (NSW Government 2019).

${ }^{3}$ In 2005 and 2006, I completed a number of interviews on older people in different housing tenures. In 2014, I returned to this focus in preparation for a book on older people and housing tenure and conducted several more interviews. In the intervening period there had been little change in the circums tances of older private renters. The light regulation of the private rental sector is still in place and rents remain extremely high. For older social housing tenants, many had to cope with more challenging neighbours due to the increasing residualisation of social housing.

${ }^{4}$ The two studies were approved by the ethics committee at the author's university.

\section{References}


Aartsen, M., and M. Jylhä. (2011) 'Onset of loneliness in older adults: Results of a 28 year prospective study', European Journal of Ageing 8 (1): 31-38.

ABS (Australian Bureau of Statistics) (2019a) More households renting as home ownership falls. Media release, 17 July. Canberra: ABS. URL (consulted 15 November 2019): https ://www.abs.gov.au/auss tats/abs@.ns f/Lookup/by\%20Subject/4130.0 201718 Media \%20Release More \%20households \%20renting\%20as \%20home\%20ownership\%20 falls $\% 20$ (Media\%20Release) 10

ABS (Aus tralian Bureau of Statistics) (2019b) Housing occupancy and costs, 2017-18. Canberra: ABS. URL (consulted 20 November 2019): https://www.abs .gov.au/AUSSTATS/abs@.ns f/Details Page/4130.02017-18?OpenDocument ABS (Australian Bureau of Statistics) (2017a) 2071.0 - Cens us of Population and Housing: Reflecting Australia - Stories from the Census, 2016. Canberra: ABS. https ://www.abs.gov.au/auss tats/abs@.ns f/Lookup/by\%20Subject/2071.0 2016 Main\%20Fe atures $\sim$ Snapshot\%20of\%20Aus tralia,\%202016 2

ABS (Australian Bureau of Statistics) (2017a) 2071.0 - Cens us of Population and Housing: Reflecting Australia - Stories from the Cens us, 2016: Ageing Population. Canberra: ABS. https://www.abs.gov.au/AUSSTATS/abs@.ns f/Details Page/2071.02016?OpenDocument ABS (Australian Bureau of Statistics) (2006) 4130.0.55.001- Housing occupancy and cos ts, Australia, 2003-2004. Canberra: ABS. https ://www.abs.gov.au/AUSSTATS/abs@.ns f/Details Page/4130.0.55.00120032004?OpenDocument 
AIHW (Australian Institute of Health and Welfare) (2019) Social Is olation and Loneliness. Canberra: AIHW. URL (Consulted 20 November, 2019)

https://www.aihw.gov.au/reports/aus tralias -welfare/s ocial-is olation-and-loneliness

AIHW (Australian Institute of Health and Welfare) (2017) Australia's Welfare 2017.

Canberra: AIHW URL (Consulted 15 November, 2019)

https://www.aihw.gov.au/getmedia/d18a1d2b-692c-42bf-81e2-47cd54c51e8d/aihwaustralias -welfare-2017-chapter5-1.pdf.aspx

Anders on, G. O. (2010) Loneliness Among Older Adults: ANational Survey of Adults 45+. Was hington, DC: AARP Research, September 2010 URL (Cons ulted 30 November, 2019). https ://doi.org/10.26419/res.00064.001

Australian Government (2019) Vulnerable private renters: Evidence and option. Canberra: Productivity Commission, Australian Government. URL (Cons ulted 25 November, 2019) https ://www.pc.gov.au/research/completed/renters/private-renters.pdf

Aus tralian Ps ychological Society (2018) Australian Loneliness Report. Melbourne: Australian Psychological Society and Swinburne University of Technology. Retrieved from https://ps ychweek.org.au/wp/wp-content/uploads/2018/11/Ps ychology-Week-2018Aus tralian-Loneliness-Report-1.pdf

Beck, U. and Beck-Gernsheim, E. (1996) 'Individualisation and Precarious Freedoms', in P. Heelas, S. Lash and P. Morris (eds.) Reflexive Modernization, Cambridge: Polity Press.

Beer, A., D., J. Faulkner, G. Law, A. Lewin, L. Tinker, L. Buys, R. Bentley, A. Watt, S. McKechnie and S. Chess man (2016) 'Regional variation in social is olation amongst older Aus tralians', Regional Studies, Regional Science 3 (1): 170-184. DOI:

10.1080/21681376.2016.1144481 
Beer, A., B. Kearins, and H. Pieters (2007) 'Housing affordability and planning in Aus tralia: The challenge of policy under neo-liberalis m' Housing Studies, 22 (1): 11-24.

British Red Cross (2017) Trapped in a Bubble: An Investigation into Triggers for Loneliness in the UK. London: British Red Cross .

Burholt, V. and T. Scharf (2014) 'Poor health and loneliness in later life: The role of depressive symptoms, social resources, and rural environment' The Journals of Gerontology Series B 69 (2): 311-324.

Cacioppo, J.T., and S. Cacioppo (2018) 'The growing problem of loneliness', The Lancet 39 (3): 426.

Cacioppo, J.T., J.H. Fowler and N.A. Chris takis (2009) 'Alone in the Crowd: the structure and spread of loneliness in a large social network' Journal of Personality and Social Psychology 97 (6): 977-99.

Cohen-Mansfield, J. and A. Parputa-Gill (2007) 'Loneliness in older persons: A theoretical model and empirical findings’ International Psychogeriatrics 19 (2): 279-294.

De Jong Gierveld J. and C. Tesch-Romer (2012) 'Loneliness in old age in Eastern and Western European societies: Theoretical perspectives', European Journal of Ageing 9: 285295.

Di Julio, B., L. Hamel, C., Munana, and M. Brodie (2018) Loneliness and social isolation in the United States, the United Kingdom, and Japan: An International Survey. Menlo Park, Calif. Henry J Kaiser Family Foundation. URL (Consulted 20 November 2019) https ://www.kff.org/othe r/report/loneliness -and-s ocial-is olation-in-the-united-s tates -theunited-kingdom-and-japan-an-international-s urvey/ 
Dykstra, P. and J. De Jong Gierveld (1999) 'Differential indicators of loneliness among elderly. The importance of type of partner relations hip, partner his tory, health, socioeconomic status and social relations', Tijdschr. Gerontol. Geriatr 30: 212-225.

Fokkema, T., J. de Jong Gierveld, and P.A. Dykstra. (2012) 'Cross -national differences in older adult loneliness', The Journal of Psychology 146 (1-2): 201-228.

Fors man, A.K., C. Herberts, F. Nyqvist, K. Wahlbeck and I. Shierenbeck,(2013)

'Understanding the role of social capital for mental well/being among older adults', Ageing and Society 33: 804-825.

Franklin, A., and B. Tranter (2011) Housing, loneliness and health, AHURI Final Report No. 164. Melbourne: Aus tralian Housing and Urban Research Ins titute.

Gerst-Emerson, K., and J. Jayawardhana (2015) 'Loneliness as a public health issue: The impact of loneliness on health care utilization among older adults', American Journal of Public Health 105 (5): 1013-1019.

Giddens, A. (1991) Modernity and Self-Identity. Self and Society in the Late Modern Age. London: Sage.

Grow S., A. Towers, P, Yeung, F. Alpass and C. Stephens (2015) 'The relationship between loneliness and perceived quality of life among older persons with vis ual impairments', Journal of Visual Impairment and Blindness 109: 487-499.

Hawkley, L.C. Cacioppo, and J.T. Cacioppo (2010) 'Loneliness matters: a theoretical and empirical review of consequences and mechanis ms', Annals of Behaviour Medicine 40: 218227. 
Heylen, L. (2010) 'The older, the lonelier? Risk factors for social loneliness in old age', Ageing and Society 30: 1177-1196.

Hiscock, R., A. Kearns, S. MacIntyre and A. Ellaway (2001) 'Ontological security and psycho-s ocial benefits from the home: Qualitative evidence on issues of tenure', Housing Theory and Society 18 (1-2): 50-66.

Holt-Lunstad, J., T.B. Smith, M. Baker, T. Harris, and D. Stephens on (2015) 'Loneliness and social isolation as risk factors for mortality: A meta-analytic review', Perspectives on Psychological Science 10 (2): 227-237.

Keene, D., M. Bader and J . Ails hire. (2013) 'Length of residence and social integration: The contingent effects of neighbourhood poverty', Health \& Place, 21: 171-178.

Kramer, S., T. Kapteyn, D. Kuik, and D. Deeg, (2002) 'The association of hearing impairment and chronic diseases with psychos ocial health status in older age', Aging Health 14: 122-137.

López Doblas, J., and P. Díaz Conde. (2018) 'Widowhood, loneliness and health in old age', Revista Española de Geriatría y Gerontología 53 (3): 128-133.

Maqbool, N., J. Viveiros and M. Ault. (2015) The impacts of affordable housing on health: A research summary. Insights from housing policy, April. https://www.rupco.org/wpcontent/uploads/pdfs/The-Impacts -of-Affordable-Housing-on-HealthCenterforHousingPolicy-Maqbool.etal.pdf

Malcolm, M., H. Frost and J. Cowie. (2019) 'Loneliness and social isolation causal association with health-related lifestyle risk in older adults: a sys tematic review and metaanalys is protocol', Systematic Reviews 8: 48: 1-8. 
McCabe, B.J. (2012) 'Homeownership and social trust in neighbours', City \& Community 11 (4): 389-408.

Meltzer, R. and A. Schwartz (2015) 'Housing affordability and health: Evidence from New York City', Housing Policy Debate 26 (1): 80-104.

NSW (2019) Issue 128 (2019) Rent Tables June Quarter 2019. Sydney: NSW Govemment. URL (Cons ulted 1 December 2019) https ://www.facs.ns w.gov.au/download?file=672626 Paris, C. (1993) Housing Australia. Melbourne: Macmillan.

Routasalo, P., and K.H. Pitkala (2003) 'Loneliness among older people', Reviews in Clinical Gerontology 13(4): 303-311.

Saunders S. J. Sim, T. Kingstone, S. Baker, J. Waterfield, B. Bartlam, H. Burroughs and C. Jinks. (2018) 'Saturation in qualitative research: exploring its conceptualisation and operationalisation', Quality and Quantity 52 (4): 1893-1907.

Savikko, N., P. Routasalo, R.S. Tilvis, T.E. Stranberg, and K.H. Pitkala (2005) 'Predictors and subjective causes of loneliness in an aged population', Archives of Gerontology and Geriatrics 41(3): 223-233.

Schermer, J.A. and N.G. Martin (2019) 'A behaviour genetic analysis of pers onality and loneliness', Journal of Research in Personality 78: 133-137.

Stanley, M., W. Moyle, A. Ballantyne, K. Jaworski, M. Corlis, D. Oxlade, A. Stoll, and B. Young (2010) . “Nowadays you don't even see your neighbours': loneliness in the everyday lives of older Australians', Health and Social Care in the Community 18 (4): 407- 414. 
Turney, K. and K. Harknett (2010) 'Neighbourhood disadvantage, residential stability and perception ins trumental support among mothers', Journal of Family Issues 31 (4): 499-524.

Victor, C.R., and K. Yang. (2012) 'The Prevalence of Loneliness among Adults: A Case Study of the United Kingdom', Journal of Psychology 146 (1-2): 85-104.

Victor, C., S. Scambler, J. Bond, and A. Bowling. (2000) 'Being alone in later life:

Loneliness, social is olation and living alone', Reviews in Clinical Gerontology 10 (4), 407 417.

Yang, K., and C. Victor (2011) 'Age and Loneliness in 25 European nations', Ageing \& Society 31: 1368-1388.

Yang, K. (2019) Loneliness: A Social Problem. Routledge: London.

Yen, I. H, Y.L. Michael and L. Perdue. (2009) 'Neighbourhood environment in studies of health of older adults: A systematic review', American Journal of Preventive Medicine, 37: 455-463.

Yildirim, Y., and S. Kocabiyik (2010) 'The relationship between social support and loneliness in Turkish patients with cancer', Journal of Clinical Nursing 19: 832-839. 